\title{
Distanciation: a key challenge for 21st Century conservation
}

\author{
Leticia Margarita Ochoa-Ochoa \\ CMEC, University of Copenhagen, \\ Copenhagen, Denmark. \\ School of Geography and the Environment, \\ University of Oxford, \\ Oxford, United Kingdom. \\ leticiaochoa@snm.ku.dk \\ Sandra Nogué \\ Oxford Long-term Ecology Laboratory, Biodiversity \\ Institute, University of Oxford \\ Oxford, United Kingdom. \\ sandra.noguebosch@zoo.ox.ac.uk
}

\author{
Rafa Devillamagallón \\ Centro Universitario de Estudios Cinematográficos, \\ UNAM. \\ México D.F., México. \\ Faculty of Humanities, \\ University of Copenhagen, \\ Copenhagen, Denmark.
}

\author{
Richard J. Ladle \\ Institute of Biological Sciences and Health, \\ Federal University of Alagoas, \\ Maceió, AL, Brazil.
}

\begin{abstract}
It can be observed that, when faced with news of environmental crises such as the impacts of climate change, many people increasingly express detachment or even denial. Given the fundamental importance of public participation in conservation action, it is clearly important to understand how this situation arose and how it might be improved. Here, we argue that growing disconnection (distanciation) from the fate of the natural world can be conceptualized as a cyclical process whereby environmental crises - as represented by the media-causes despair and denial, limiting participation in societal-level conservation interventions and decreasing the effectiveness of conservation actions. We propose a strategy to reduce and possibly reverse distanciation, focusing on biodiversity responses to climate change. In doing so we hope to raise awareness about the undesirable (and unintended) consequences of promoting biodiversity conservation through emphasizing negative outcomes, thereby altering perceptions about the current state and future of wild nature and jeopardizing the capacity of individuals to influence outcomes.
\end{abstract}

Keywords-climate change; cognitive dissonance; compassion fatigue; despair; distanciation; environmental crisis; mass media.

\section{INTRODUCTION}

Effective communication of science through the mass media (newspaper, TV news, magazines, and internet) is an important, if undervalued, task in all scientific areas [1]. This is especially true for a values-driven discipline such as conservation science, whose legitimacy and effectiveness depends on public support. Conservation scientists who engage with the media therefore need to consider how the scientific information they are providing is going to be interpreted, given that the vocabulary, dynamics, and the goals of reporting science in the popular media differ substantially from those in scientific journals [2]. Good communication between science and mass media is particularly important when it comes to addressing complex and inherently uncertain conservation issues such as the impacts of climate change on biodiversity or forecasts of global rates of species extinction [3] or for explaining the future impacts upon human daily-life. In summary, one of the key challenges of communicating conservation science is to make people aware that "human societies have been built on biodiversity" [4, p. 1], and that to preserve biodiversity is to look after the long-term survival of human societies.

Good communication in conservation science exists. Nevertheless, much conservation science reporting in the mass media is sensationalist and inaccurate, emphasizing worst-case scenarios and typically projecting an inappropriate level of certainty[5]-[10]. Moreover, doom-mongering is not restricted to the mass media - the environmental prospects offered at the start of the Millennium Ecosystem Assessment (MA) have been characterized as the worst people could expect [11]: the Earth is too polluted, deforestation is out of control, population growth is unchecked, and there is a lack of economic and political will to solve the problem. Indeed, impending environmental catastrophes (overpopulation, pollution, extinction, climate change) have been an everyday feature of the popular media for the last half-century [5], [12].

Despite its prevalence, the impact of environmental alarmism on society is virtually unknown, although research in this area is increasing [13]-[15]. So far, the results suggest that it is imperative a new model of science communication [13] because some surveys indicate that "information-based science advocacy has had only a minor effect on public concern" [14] and the main reason seems to be a conflict of interests between the personal interests and those of the community.

In a web-based survey, we asked 61 people from different nationalities which media content disturbed them the most. 
From the fifteen possible answering options, "Information about environmental degradation and lack of natural resources" turned out to be the third most disturbing just after political documentaries and the horror genre (fictional). However, from these three, environmental information stood out as the one most prone to influence the behavior of the respondents. This suggests that people is willing to cooperate on conservation programs. Environmental issues were also - out of the fifteen options - the content reported as the less intended to be avoided by our participants; which stood against the overall positive correlation between avoidance and distress in our study, pointing out the category as an exceptional case within the field and one susceptible to controversy and misinterpretations.

One of the big issues in miscommunicating science is the dangers of hype-inspired misinterpretations are outweighed by the ability of sensationalized science to raise public awareness about important environmental issues [16]. There is an unwritten logic that, if science is to effectively communicate with the public, it must employ attention-grabbing headlines, delivers periodic "breakthroughs", and, most importantly, endows research findings with personal significance for readers. Other scientists suggest that hyping impending environmental crises turns people off, promotes nihilism and may even block the mass behavioral change that environmentalists desire [8]. However, participation of scientists in media hype risks undermining public trust in scientists and the credibility of science as a basis for public policy [7].

Here, we provide a novel perspective on environmental alarmism, arguing that the drip feed of disaster stories is creating "emotional numbness" [17], and therefore increasing dissociation of citizens (and the societies to which they belong) from nature. Countering the effects of such distanciation will require a radical rethinking of how environmental scientists communicate and interact with the mass media. Because environmental crisis covers such a wide range of topics we focused on climate change, specifically global warming.

\section{Distanciation}

Sutherland et al. [18] identified the impacts of "increasing human disassociation from nature on the conservation of biodiversity" (p. 565) as one of the 100 most important issues in global conservation. Identifying and countering these impacts requires a clear understanding of the causes and process of the dissociation, drawing on research and concepts from diverse fields. One useful concept is distanciation. This was brought into environmental sciences by McManus [19]; but its roots can be traced back to Giddens [20] who coined it to describe how social systems unfold across time or space without all its entities necessarily connected across those; but rather by participating "in some form of dissolution of the restraints of time and space" (p. 91). Henning proposed later that such dissolution leads to a "weakening of social bonds" [21] and a lost of trust on one another. The term was also used by Gould [22, p. 381], who defined it as the psychological process of: "removing ourselves from the immediate vicinity, but... still within the general realm of concern". McManus [19, p. 306] provides a more practical definition of distanciation as the 'separation of cause and effect in regard to an issue'. This process of separation begins when an audience perceives the message as important while at the same time feeling disempowered to influence the projected course of events.

In the context of conservation, distanciation can be conceptualized as a closed process that we have named Cycle of distanciation (Fig. 1), whereby inaction and denial emerges in response to media coverage of a crisis. This, in turn, leads to a lack of mass action and, therefore, increasingly bleak environmental prognoses. At the start of the cycle there is a fact, in this case, climate is changing. Based on that fact predictions of impacts and future scenarios are generated, creating concern. At this step, predictions, extreme environmentalist statements and other type of information, such as astroturfing (misleading/deceptive advertising) and pseudoscience are converted to taglines. These taglines along with the factual information are the sources of the mass media; nevertheless within mass media all this information is mixed and transferred to the public. At this stage the public wants to act but they have, at best, an unarticulated understanding of the complex processes occurring in nature. This unarticulated understanding takes the public, mainly, by two different roads leading to the same destination. On one path to unstructured actions and green consumerism, but at the end nothing changes, causing despair and compassion fatigue crystallizing on distanciation. On the other, different messages generate cognitive dissonance causing denial leading, also, to distanciation.

There are two main feedback loops within the Cycle of distanciation (Fig. 1): i) the separation of cause and effect by the media during the translation of science into news undermines behavioral change messages because the public are unable to make direct links between the actions that they are being asked to adopt and the looming inevitability and enormous scale of the environmental crisis the media is reporting. Inevitably, this leads to despair and inaction. ii) The lack of meaningful environmental improvements over the short time scale of the media reporting (compared to the typically long time scale of the environmental deterioration) diminishes credibility about the efficacy of action and the veracity of media reporting. When action does not lead to rapid improvements, 'compassion fatigue' [23] sets in and environmental issues are more likely to be ignored or treated with weary cynicism. Denial might also get promoted by cognitive dissonance: the clash between what is being reported by scientist and other sources of information using science-like language (e.g. anti-environmentalist websites, politicians, social networks) [13], [24], in conjunction with the fact that most people can continue their daily activities without any real disaster.

Two types of distanciation can be distinguished: temporal and spatial. The process of temporal distanciation can be clearly illustrated by the abundant literature (both academic and popular) on the effects of climate change in biodiversity. For example, the following was written in a high profile scientific article published in the journal Nature in one of the most cited papers regarding climate change [25]: "we predict, 


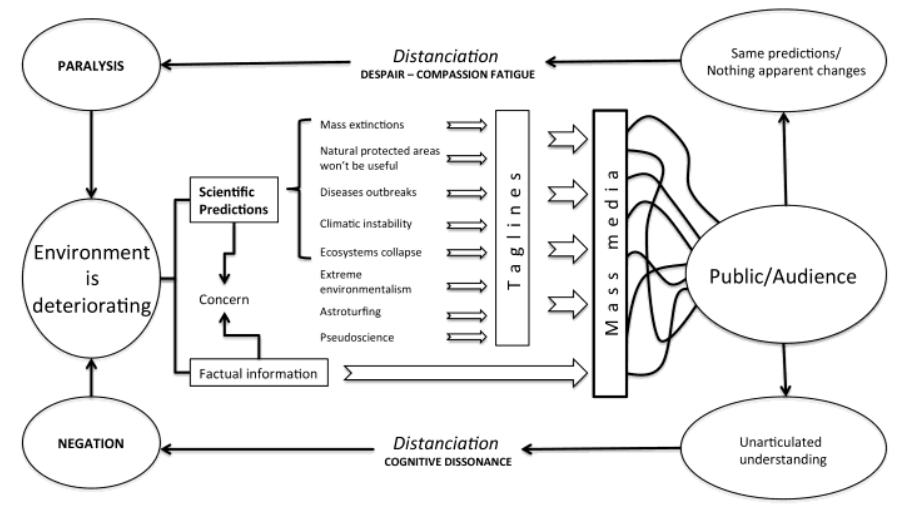

Fig. 1. Cycle of distanciation.

on the basis of mid-range climate-warming scenarios for 2050, that $15-37 \%$ of species in our sample of regions and taxa will be "committed to extinction"". The public could interpret this as "the disaster is going to occur or begin around 2050". Indeed, this is how the global news media reported this study [6], [9]. The environmental problem is the result of causes (e.g. climate change) that are occurring in the present moment, but the consequences (e.g. extinction) will be far-reaching, probably far greater than the life expectancy of many of the readers of the same media. Thus, the audience does not feel urgency for action.

An example of spatial distanciation - the existence of geographical space between causes and effects - can be seen in developed-world government rhetoric about the success of environmental initiatives (e.g. recycling programs, large protected areas, clean energy production). Though some might be well intentioned, the ultimate effect of such rhetoric could be that citizens perceive environmental problems as something 'belonging' to developing countries with poor governance. Disregarding completely the fact that important quantities of goods come from those countries which just absorb the environmental and social costs of production [26], [27]. The contrast between the pessimism of much media reporting and the optimism associated with many government reports may be even greater in developing countries that are trying to ascend by convincing others of their stability and social responsibility. The cognitive dissonance that results from receiving two radically different messages may result in widespread denial. Ultimately, in both scenarios, citizens become tired (fatigued) of the constant onslaught of environmental bad news [17], making it incrementally harder to promote conservation actions.

\section{Mass Media, Climate Change ANd Society}

A twenty-year study (1975-1995) based in Germany, demonstrated that the media ignored the uncertainties of several scientific studies about climate change and transformed them into a sequence of events leading to catastrophe and requiring immediate action [5]. More generally, dramatic statements in the media that overstate the scientific evidence have been a re-occurring problem for conservation actions and policies. For example, Sinervo and coauthors [28] stated "Global extinctions projections were validated with local extinction observed from 1975 to 2009 for regional biotas on four continents, suggesting that lizards have already crossed a threshold for extinctions caused by climate change". This paper was translated in the media as: "Lizards succumb to global warming" (Nature News; May 13, 2010). This in turn lead to the following newspaper headlines: "Heat has deadly effect on lizard's breeding: Global warming blamed for keeping females in hiding, away from food" (The Washington Post, May 14, 2010); "Warming imperils lizards, scientists warn" (The New York Times, Green blog, May 14, 2010); "Lizards are dying out because of climate change, study says" (The Independent, May 14, 2010), "Climate change to kill off a fifth of world's lizards: study" (Ibid.); "Climate change threaten lizards with extinction” (The Telegraph, January 2, 2011).

In the above case three main factors contributed to the distanciation: placing space between the scientific report and the news, and between the news and the audience. First, the word "Lizards" is a general term for a vast number of species. At the moment of publication of [26] there were 5,354 described species (http://www.reptile-database.org/data/); nowadays there are 5,987 species of lizards [29] with a great deal of different life strategies. In this study, the authors have studied 48 species. Second, according to the projections, 12\% of the local populations have gone extinct. They validated the projection models with the populations sampled. However, it is well known that such models are complex and highly sensitive to a number of parameters [30]-[32]. Such technical complexity is largely removed from the news reports. Finally, if the media's message is that lizards are doomed, as they have already crossed the extinction threshold, it is likely to promote despair rather than action. Why support conservation if the lizard's species are already lost and others animal and plant groups are likely to join them?

Addressing conservation crises at different temporal/spatial scales cannot be simplified or even addressed quickly, because it is likely to be deeply counter-productive. For example, recycling and using the bike instead of a car, of course it helps but even if, all the people in the world performed these actions, will not solve the environmental crisis. Thus, the public might feel used or cheated, suspecting the involved parts had appealed to their deepest sentiments 'apparently' for nothing [33]. Such feelings inevitably lead to apathy, generating more distanciation towards the environmental problems (that require mass action) and further despair within environmentally conscious people who justifiably feel that they are "losing the battle".

We would argue that when societies cannot imagine a better future, pessimism and despair inevitably follows. Despair almost always compromises people's capacity to act forcefully and decisively, and to improve things on behalf of others [34]. It can also undermine confidence, because individuals feel powerless to bring about desired changes and believe that nothing they can do will matter [35]. Despair leads people either to give up 'the elusive quest' entirely or to 
proceed self-indulgently to 'do one's own thing' - a socially acceptable and frequently condoned option in many western societies [36]. The sense of community is thus undermined and the notion of striving for the greater good begins to dissipate.

Finally, although we have not discussed the distanciation process in the context of the "online" world, the power of search engines (e.g. Google) or social networks (e.g. Facebook and Twitter) are essential in communicating science. Indeed, in the future the dynamics of online communication systems may have a stronger impact on public views than the specific research that we as scientists are trying to communicate [37]. Nevertheless, it is important to note that Weblog Journalism is predominantly motivated by militancy, representing a niche for challenging mainstream journalism [38]. At the same time, while institutional journalism still has guidelines regarding ethics and credibility, blogs remain open and free. Furthermore, since they do not have a captive audience, they have to remain even more egregious than their institutional counterparts [39]. Besides, for final users, looking for specific information can be exhausting and might be also very problematic for them to distinguish between the actual trustworthy material from the useless or decontextualized one, leaving them at the mercy of the websites that pay to appear on top on the 'results' of the search engines [40]; which are very often those that belong to a traditional medium (newspaper, broadcaster, etc.). In the end, the huge amount of information that can be found on the web, promotes a diversity that is often understood as beneficial, but can also overwhelm and mislead users' opinions [40], eliciting distanciation.

\section{BREAKING THE LOOP OF DISTANCIATION}

The closed feedback cycle of distanciation probably emerged while the global environmental crisis first became news more than 60 years ago [41]. Around the same time the world economy needed re-activation and a consumerist culture was strongly promoted by many mass media sources. The long and recurrent exposure to antithetical and contradictory media messages about environmental crises and consumerism has arguably created: 1) widespread compassion fatigue - a gradual lessening of caring - in society, and 2) the decoupling of consumerism as the ultimate cause of environmental problems. Prolonged exposure to such disarticulated messages has caused hopelessness and despair to emerge, seriously compromising the capacity of society to act. Individuals have psychologically retreated, protecting themselves from failure and hopelessness and even resorting to denial.

Our view is that conservation desperately needs to retain hope e.g. [42]-[44] and, conversely, it is absolutely crucial to avoid despair. As Halpin [45, p. 6] noted: "Despair itself is the enemy of progress because in the final analysis it lacks a faith in the future". If no better future is promoted, certainly "no better future" can be constructed. Unfortunately, there are no simple solutions to the problem of environmental distanciation, and any responses will require concentrated action by both scientists and citizens with full involvement of governments. Otherwise it becomes a futile struggle.
There are various ways in which scientists can contribute to reducing or avoiding distanciation: 1) avoid providing potentially misleading extrapolations or 'soundbites'; 2) carefully draft press releases and responses to questions from the media; 3) provide succinct summaries of their articles written in layman's terms (explaining complex issues in the most simple terms) which are published on institutional web sites as soon as media coverage is initiated; 4) engage with the public, and your community through your institution. For example including citizens to generate data/science, using boundary organizations and being part of the dialogues of science-policy (e.g. through popular literature or disclosure, inter alia conferences, blogs, micro-blogs, websites and talking with your neighbors). Finally, 5) have faith in civil society and not give up, for when science is communicated clearly and linked with positive actions, individuals are likely to take part.

Reconnecting humans with nature, and breaking the loop of distanciation requires societies to realize that even though humans have a negative effect on ecosystems, they also have the skills to successfully conserve and manage nature. Conservation success stories (and there are many) demonstrate that to a large extent; we can choose the survivors [46]. Thus, we can prioritize and implement tools that help reduce the gap between assessment and implementation, and allocate (or reallocate) resources to different places to reinforce and enlarge pre-existing protected area networks.

In the case of non-human species, it is possible to provide pathways: corridors through social initiatives, i.e. private or community reserves, environmental zoning plans and even through the establishment of infrastructure for environmental service provision e.g. [47]-[49]. However, these efforts are likely to be ineffective if we don't successfully bring society closer to nature.

\section{ACKNOWLEDGEMENTS}

L Ochoa PhD research was supported by CONACYT and SEP, and currently has postdoctoral fellowship granted by CONACYT. S Nogué is funded by The Norwegian Academy of Science and Letters. R Devillamagallón is funded by CONACYT and Fundación INBA. We thank R Grenyer for his helpful comments on earlier versions of this manuscript. The authors are grateful to A Massey for the constructive criticism and improving the English style of the manuscript.

\section{REFERENCES}

[1] R. J. Ladle, "Catching fairies and the public representation of biogeography," in Journal of Biogeography, 2008, vol. 35, no. 3 , pp. 388-391.

[2] S. M. Friedman, S. Dunwoody, and C. L. Rogers, Communicating uncertainty: media coverage of new and controversial science. Mahwah, NJ: Lawrence Erlbaum Associates, Inc., 1999.

R. J. Ladle and P. Jepson, "Origins, Uses, and Transformation of Extinction Rhetoric," Environment and Society: Advances in Research, vol. 1, no. 1. pp. 96-115, 2010. 

2000

R. J. Ladle, P. Jepson, M. B. Araújo, and R. J. Whittaker, "Dangers of crying wolf over risk of extinctions," Nature, vol. 428, p. 799, 2004.

[7] R. J. Ladle, P. Jepson, and R. J. Whittaker, "Scientists and the media: the struggle for legitimacy in climate change and conservation science," Interdiscip. Sci. Rev., vol. 30, no. 3, pp. 231240, 2005.

[8] G. Ereaut and N. Segnit, "Warm Words How are we telling the climate story and can we tell it better?," Public Policy Research, vol. 2006, no. August. p. 32, 2006

[9] R. Pearson, Driven to extinction. The impact of climate change on biodiversity. New York, 2011.

[10] R. Cox, Environmental communication and the public sphere, Third. London: SAGE, 2012.

[11] R. B. Norgaard, "Finding hope in the millennium ecosystem assessment," Conserv. Biol., vol. 22, no. 4. pp. 862-869, 2008.

[12] I. Lorenzoni, S. Nicholson-Cole, and L. Whitmarsh, "Barriers perceived to engaging with climate change among the UK public and their policy implications," Glob. Environ. Chang., vol. 17, no. 3-4, pp. 445-459, 2007.

[13] N. Pidgeon and B. Fischhoff, "The role of social and decision sciences in communicating uncertain climate risks," Nat. Clim. Chang., vol. 1, no. 1, pp. 35-41, Mar. 2011.

[14] R. J. Brulle, J. Carmichael, and J. C. Jenkins, "Shifting public opinion on climate change: an empirical assessment of factors influencing concern over climate change in the U.S., 2002-2010," Clim. Change, vol. 114, no. 2, pp. 169-188, Feb. 2012.

[15] D. M. Kahan, E. Peters, M. Wittlin, P. Slovic, L. L. Ouellette, D. Braman, and G. Mandel, "The polarizing impact of science literacy and numeracy on perceived climate change risks," Nat. Clim. Chang., vol. 2, no. 10, pp. 732-735, 2012.

[16] L. Hannah and B. Phillips, "Extinction-risk coverage is worth inaccuracies.," in Nature, 2004, vol. 430, no. 6996, p. 141.

[17] S. C. Moser, "More bad news: the risk of neglecting emotional responses to climate change information," in Creating a Climate for Change: Communicating Climate Change and Facilitating Social Change, S. C. Moser and L. . Dilling, Eds. Cambridge, UK: Cambridge University Press, 2007, pp. 64-80.

[18] W. J. Sutherland, W. M. Adams, R. B. Aronson, R. Aveling, T. M. Blackburn, S. Broad, G. Ceballos, I. M. Côté, R. M. Cowling, G. a B. Da Fonseca, E. Dinerstein, P. J. Ferraro, E. Fleishman, C. Gascon, M. Hunter, J. Hutton, P. Kareiva, A. Kuria, D. W. Macdonald, K. Mackinnon, F. J. Madgwick, M. B. Mascia, J. McNeely, E. J. Milner-Gulland, S. Moon, C. G. Morley, S. Nelson, D. Osborn, M. Pai, E. C. M. Parsons, L. S. Peck, H. Possingham, S. V Prior, a S. Pullin, M. R. W. Rands, J. Ranganathan, K. H. Redford, J. P. Rodriguez, F. Seymour, J. Sobel, N. S. Sodhi, A Stott, K. Vance-Borland, and a R. Watkinson, "One hundred questions of importance to the conservation of global biological diversity.," Conserv. Biol., vol. 23, no. 3, pp. 557-567, Jun. 2009.

[19] P. A. McManus, "Beyond Kyoto? Media Representation of an Environmental Issue," Aust. Geogr. Stud., vol. 38, no. 2000, pp. 306-319, 2000

[20] A. Giddens, "Time-Space Distanciation and the Generation of Power," in A Contemporary Critique of Historical Materialism, Stanford University Press, 1995, pp. 90-108.

[21] C. Henning, "Distanciation and Disembedding," The Blackwell Encyclopedia of Sociology. Blackwell Publishing Ltd, Oxford, UK, Malden, USA and Carlton, Australia, 20-Nov-2007.

[22] P. Gould, "Reflective distanciation through a metamethodological," Environ. Plan. B Plan. Des., vol. 10, pp. 381-392, 1983.

[23] S. D. Moeller, Compassion fatigue: how the media sell disease, famine, war, and death. New York: Routledge, 1999.

[24] K. Trenberth, "More knowledge, less certainty," Nature Reports Climate Change, no. 1002. pp. 20-21, 2010.

[25] C. D. Thomas, A. Cameron, R. E. Green, M. Bakkenes, L. J. Beaumont, Y. C. Collingham, B. F. N. Erasmus, M. F. De Siqueira, A. Grainger, L. Hannah, L. Hughes, B. Huntley, A. S. Van Jaarsveld, G. F. Midgley, L. Miles, M. a Ortega-Huerta, a T. Peterson, O. L. Phillips, and S. E. Williams, "Extinction risk from climate change.," Nature, vol. 427, no. 6970, pp. 145-148, Jan. 2004.

[26] E. F. Lambin and P. Meyfroidt, "Global land use change, economic globalization, and the looming land scarcity.," Proc. Natl. Acad. Sci. U. S. A., vol. 108, no. 9, pp. 3465-3472, 2011.

[27] T. O. Uribe, M. E. Mastrangelo, D. V. Torrez, A. Piaz, M. Vallejos, J. Eduardo, S. Ceja, F. Gallego, L. C. Peña, N. E. Mellado, J. F. Flores, R. G. Mairhofer, Z. G. Espino, L. Salguero, C. M. Martinezperalta, O. Ochoa, L. P. Volkow, J. Emilio, I. Sánchez-rose, M. Weeks, D. Á. García, I. Bueno, A. Carmona, F. C. Videla, C. S. Ferrer, M. Elisa, F. Buss, G. L. Carapia, M. N. Cruz, R. T. Hermoza, D. Benet, Y. Venegas, P. Balvanera, T. H. Mwampamba, E. L. Chavero, E. Noellemeyer, and M. Maass, "Estudios transdisciplinarios en socio-ecosistemas: reflexiones teóricas y su aplicación en contextos latinoamericanos," Investig. Ambient., vol. 6, no. 2, pp. 123-136, 2014.

[28] B. Sinervo, D. B. Miles, N. Martinez-Mendez, R. Lara-Resendiz, and F. R. Mendez-De la Cruz, "Response to Comment on 'Erosion of Lizard Diversity by Climate Change and Altered Thermal Niches,"” Science (80-. )., vol. 332, no. 6029, pp. 537-537, Apr. 2011.

[29] P. Uetz and J. Hošek, “The Reptile Database," 2014. [Online]. Available: http://www.reptile-database.org/dbinfo/SpeciesStat.html. [Accessed: 15-Mar-2015].

[30] R. G. Pearson, W. Thuiller, M. B. Araújo, E. Martinez-Meyer, L. Brotons, C. McClean, L. Miles, P. Segurado, T. P. Dawson, and D. C. Lees, "Model-based uncertainty in species range prediction," $J$. Biogeogr., vol. 33, no. 10, pp. 1704-1711, Oct. 2006.

[31] L. M. Ochoa-Ochoa, P. Rodríguez, F. Mora, O. Flores-Villela, and R. J. Whittaker, "Climate change and amphibian diversity patterns in Mexico," Biol. Conserv., vol. 150, no. 1, pp. 94-102, 2012.

[32] R. J. Whittaker, M. B. Araújo, P. Jepson, R. J. Ladle, J. E. M. Watson, and K. J. Willis, "Conservation Biogeography: assessment and prospect," Divers. Distrib., vol. 11, no. 1, pp. 3-23, Jan. 2005.

[33] M. J. Costello, R. M. May, and N. E. Stork, "Can we name Earth's species before they go extinct?,” Science (80-. )., vol. 339, no. 6118, pp. 413-416, 2013. 
[34] R. M. Nesse, "The Evolution of Hope and Despair," Soc. Res. (New. York)., vol. 66, no. 3, pp. 429-469, 1999.

[35] A. Reading, Hope and despair: How Perceptions of the Future Shape Human Behavior. London: The Johns Hopkins University Press, 2004.

[36] Y. Lapid, "The Third Debate: On the Prospects of Era Internationa Theory in a Post-Positivist Era," Int. Stud. Q., vol. 33, no. 3, pp. 235-254, 1989.

[37] D. Brossard and D. a Scheufele, "Social science. Science, new media, and the public.," Science (80-. )., vol. 339, no. 6115, pp. 4041, Jan. 2013.

[38] D. Matheson, "Weblogs and the Epistemology of the News: Some Trends in Online Journalism," New Media \& Society, vol. 6, no. 4 pp. 443-468, 2004.

[39] A. Bruns, "News Blogs and Citizen Journalism: New Directions for e-Journalism," in e-Journalism : New Media and News Media, 2009.

[40] D. McQuail, McQuail's Mass Communication Theory, Sixth Edit. SAGE, 2010.

[41] L. W. Moncrief, "The Cultural Basis for Our Environmental Crisis," Science (80-. )., vol. 170, no. 3957, pp. 508-512, 1970

[42] D. W. Orr, "Hope in hard times," Conserv. Biol., vol. 18, no. 2, pp. 295-298, 2004.
[43] D. W. Orr, "Optimism and hope in a hotter time," Conserv. Biol., vol. 21 , no. 6 , pp. 1392-1395, 2007

[44] C. O. Webb, "Engineering hope," Conserv. Biol., vol. 19, no. 1, pp 275-277, 2005 .

[45] D. Halpin, "The Nature of Hope and its Significance for Education," Brit. J. Educ. Stud., vol. 49, no. 4. pp. 392-410, 2001.

[46] L. M. Ochoa-Ochoa, J. E. Bezaury-Creel, L. B. Vázquez, and O. Flores-Villela, "Choosing the survivors? A GIS-based triage support tool for micro-endemics: Application to data for Mexican amphibians," Biol. Conserv., vol. 144, no. 11, pp. 2710-2718, 2011.

[47] L. Ochoa-Ochoa, J. N. Urbina-Cardona, L.-B. Vázquez, O. FloresVillela, and J. Bezaury-Creel, "The effects of governmental protected areas and social initiatives for land protection on the conservation of Mexican amphibians.," PLoS One, vol. 4, no. 9, p. e6878, Jan. 2009

[48] R. F. Baldwin, R. B. Powell, and S. R. Kellert, "Habitat as Architecture: Integrating Conservation Planning and Human Health," AMBIO A J. Hum. Environ., vol. 40, no. 3, pp. 322-327, 2011.

[49] C. Schleupner and U. A. Schneider, "Allocation of European wetland restoration options for systematic conservation planning," Land use policy, vol. 30, no. 1, pp. 604-614, 2013. 